Public health policy

\section{A tentative step towards healthy public policy}

\author{
Michael Joffe, Jennifer Mindell
}

\section{More consistent attention to implementing healthy public policy, and amassing the evidence for it, are urgently required.}

$\mathrm{H}$ ealth has improved greatly in recent decades, both in the developed world and much of the developing world. Nevertheless, many health problems remain, and in particular, social inequalities in health are not diminishing. Recently there has been considerable concern about the rapid increase in obesity and related conditions such as adult onset diabetes, yet the debate remains largely phrased in terms of health education and individual behaviour. In addition, some grave health problems seldom even enter public debate, as they are not increasing-for example, we have become so accustomed to slaughter and maiming on the roads that road deaths are rarely even counted as newsworthy.

\section{THE WANLESS REPORT}

In the United Kingdom, a recent report from the Treasury (finance ministry), the "Wanless Report", explores the ways that population health can be improved and health inequalities reduced. This contribution to the health debate has a significance that goes beyond the British context, as it deals with issues that are relevant throughout the economically developed world. Arguably they are even more important in less well off regions, but the terms of the debate are considerably different in that context and will not be further considered here.

The report represents an important step forward-but also a step to the side. It builds on a previous report in 2002, also by Derek Wanless, ${ }^{2}$ on the funding of the NHS, which considered that the recent substantial UK investment in health care would lead to large health gains only if population health also improved significantly through individuals' involvement in their own health, "the fully engaged scenario". The focus of the more recent report is on how to achieve this, the starting point being that prevention is more cost effective than provision of health care to treat disease. It also accepts that past and current public health approaches may have contributed to widening health inequalities.

The report notes that the major drivers of public health have been known since the 1970s, yet despite some successes, implementation has at best been partial and requires a step change in effort and achievement. In particular it notes that while the scientific justification for action is often strong, the evidence base on the cost effectiveness of preventive policies and their practical implementation is weak, and that this is related to lack of funding for public health intervention research. Information is particularly scarce on interventions that could reduce health inequalities due to, say, smoking or obesity. The lack of a comprehensive evidence base should not, however, be an excuse for inertia; rather, existing initiatives should be evaluated as a series of natural experiments.

In summarising the roles and responsibilities of different agents, the report rejects the view that all decisions should be left completely up to each individual, as people may not have sufficient scientific information, may be unable to accurately balance risks and benefits, and may lack a supportive social context. This is particularly important in relation to social inequalities in health. Shifting social norms is a legitimate activity for government where it has set national objectives for behaviour change. The report concludes by reviewing the levers available to governmenttaxes, subsidies, service provision, regulation, and information-with a particularly lucid section on fiscal policies.

\section{THE MAJOR IMPACT OF HEALTHY} PUBLIC POLICY

Nevertheless, the report places insufficient emphasis on the extent to which large health gains have historically resulted from healthy public policy, in the sense of regulation, fiscal policy, and the provision of reliable information other than health education campaigns, as well as other types of initiative such as infrastructure construction projects. Sometimes this is without even having health improvement as a major objective, as was originally the case with tobacco taxation.

One of the most dramatic of all historical processes has been the decline in the major infectious diseases that used to dominate society, especially affecting the poor, which has occurred in all economically advanced societies. This was mainly attributable to improved food supply and the provision of sewerage and clean water, ${ }^{3}$ together with socio-political action. ${ }^{4}$ Similar measures remain a priority in poor regions of the world.

Subsequent government actions have also played an important part in improving health. For example, in the UK these have included the Clean Air Act of 1956 that put an end to the lethal smogs that had occurred in London and elsewhere during the earlier 1950s. While the health impact is only now being assessed, ${ }^{5}$ a ban on coal sales in Dublin in 1990 is estimated to have saved over 350 lives a year in a population of less than a million. ${ }^{6}$

A more recent UK example is a tax advantage that was given to unleaded petrol in 1989, which resulted in rapidly declining environmental lead levels, ${ }^{7}$ with probable important benefits on the neurological development of children, especially those from deprived backgrounds. ${ }^{8}$ Other important transport related measures have been the introduction of the breathalyser and speed control, which have greatly reduced road deaths and serious injuries. ${ }^{9}$ And although health was not a major motivating factor in their introduction, policy initiatives by the current government aiming at economic redistribution, such as the goal of full employment and the use of tax credits to reduce poverty, are likely to have had major beneficial health impacts. ${ }^{10}$

There is a reason for the effectiveness of healthy public policy: Rose famously pointed out that whereas identifying people at high risk, for example, of raised blood pressure, and treating them individually was a never ending task, as each year more people would enter this high risk category, a "whole population" approach would produce a once for all change in the population, as long as it remained in effect. ${ }^{11}$ This applies particularly strongly to healthy public policy, because strategies that rely on health education can be interfered with by new fads such as the Atkins diet, or fears about immunisation with MMR (measles, mumps, and rubella) vaccine. In contrast, in the UK cholera has not returned and tuberculosis (although increasing) is rare compared with its ravages in the 19th century; smogs from coal burning have disappeared; lead 
exposure remains low; alcohol and speed related road casualties are lower than they were-although further action here is warranted. ${ }^{9}$

\section{Inequalities}

People with more education and socioeconomic resources tend to respond more to health education, thereby tending to increase inequalities. ${ }^{12}$ One advantage of healthy public policy is that the impact is typically felt across the whole population. Thus, with tobacco taxation, people on lower incomes are more responsive to price increases. ${ }^{12}$ However, healthy public policy strategies do not inevitably reduce inequalities, and case by case analysis is needed. For tobacco taxation, it depends on alternative cheaper sources of tobacco not being available, ${ }^{13}$ Customs and Excise staff having sufficient resources to tackle smuggling and illicit sales of contraband,,$^{14}$ and there being support for smokers who remain addicted (for example, through targeted cessation support and increased child benefit). Otherwise, low income people increase their expenditure on tobacco, leaving even less disposable income available for food, housing, and other essentials. In this way social inequalities may increase, and this has health and other implications. Such inequality is not solely socioeconomic in origin, as it also applies to those with psychological or psychiatric problems who use tobacco as a crutch.

\section{The costs of healthy public policy interventions}

The financial costs of healthy public policy interventions are typically comparatively small. They can even generate revenue, as with tobacco taxation. While this can lead to public relations difficulties-with speed cameras being attacked in the press as merely money making devices, and the success of the London Congestion Charge Scheme portrayed as a financial failure because traffic levels fell "too much"—it can undoubtedly be an advantage.

In other circumstances, the case for an intervention is that it redresses hidden costs. Thus, while the road lobby compares what drivers pay in taxes with the cost to government of providing infrastructure, the true cost includes also road deaths and injuries, air pollution, etc. ${ }^{9}$ Economists, including Wanless, call these wider costs to society that fall outside the transaction between driver and government "externalities", and recommend taxation at a level that "internalises" them. ${ }^{15}$ To make this possible, the analysis of health impacts has to be augmented by economic valuation of the various health (and other) outcomes.

A small expenditure can be very effective. In early 1989, most UK car drivers were reluctant to convert their engines to lead free petrol; industry saw no demand for lead free pumps at petrol stations. A slight tax advantage for lead free petrol in the Budget was followed by a rapid change in behaviour of both groups, with beneficial effects as noted above. This raises another point: although likely to have been "profitable" on the basis of internalising the externality, this action was probably justifiable even if it were not: as Wanless says, sometimes the health gain outweighs the economic argument-it is worth paying for. ${ }^{1}$

\section{THE NEGLECT OF HEALTHY PUBLIC POLICY}

We have seen that healthy public policy can be highly effective and has an impressive track record, that it does not increase inequalities in the way that health education typically does, and that it tends to have low costs. Nevertheless, implementation of healthy public policy interventions is piecemeal. In addition, there is an apparent tendency in recent decades for their scope to become more tentative, although still important.

Even the Wanless Report, while accepting the role of healthy public policy in tobacco control, does not produce clear recommendations in areas of more recent concern such as obesity, nutrition, and physical activity. It considers a "fat tax", and subsidised gym membership, which it rejects for good reasons, but does not analyse diet and physical activity in relation to existing or potential policies in the food/agriculture industry and transport.

Why then is healthy public policy not routinely considered as a major means of tackling health problems? It could be that governments are uneasy about the wider economic and social effects, and/ or the ideological reaction to such interventions. If so, these concerns need to be analysed, just as they are when environmental criteria are considered across the broad range of government policy.

\section{Indirect "costs" and trade offs}

Apart from the costs of implementation that tend to be low, there are other types of "cost" that have to be considered. As with the impact on social inequalities, a case by case analysis is required.

The most important is employment. Even with a product as harmful as tobacco, it needs to be recognised that the tobacco industry is an important employer in a few areas of the country. We need to consider whether reducing tobacco consumption would mean reducing employment. In fact, job loss has been mainly attributable to automation, not lower production. ${ }^{16}$ Furthermore, as cigarette production is not labour intensive, money spent by former smokers on other things generates more employment: a $40 \%$ reduction in tobacco consumption would create about 150000 jobs in the UK. ${ }^{16}$ There is also the ethical argument: most people would not oppose a road safety campaign to protect employment in the car bodywork repair industry.

\section{Principle and ideology}

More recently, arguing for healthy public policy in the UK has had to deal with a libertarian reaction, summed up in the phrase "the nanny state", implying that the state is telling people what to do, thereby interfering with personal freedom. This has introduced an unnecessary defensiveness into attempts to tackle current health priorities, such as rising obesity and associated conditions. When the health problem concerned is important, as with lung cancer, increasing obesity and related problems, or road deaths and injuries, government "interference" is more justified than for less serious and/or widespread conditions. Given sufficient explanation, action is likely to be acceptable if the costs (of all kinds) are proportionate to the benefits.

While libertarian opposition is nothing new, it now tends to have a dismissive tone, ignoring arguments about competing rights; for example, smoking bans in public places (endorsed by Wanless, subject to further evidence) can readily be defended in terms of freedom to breathe smoke free air. The same argument applies to other types of pollution, and to the right to consume food free of excess hidden fats, sugar, and salt. It is analogous to the government's accepted role of ensuring that food additives must be safe: the whole population benefits, not just those with the toxicological knowledge, time, and motivation to scrutinise labels.

Perhaps less reliance on telling people what to do, and more emphasis on making healthy choices easier, would find readier acceptance. This would require a state that is clever, prudent, capable, and shrewd, in other words a "canny state". It is more promising than simply re-iterating the healthy living messages.

\section{IMPLEMENTATION}

Healthy public policy has an ample track record despite never having been systematically adopted by any government worldwide. Yet this marginalisation continues except in a few areas such as 
tobacco control and food safety. Admittedly the evidence base needs to be improved, which requires more financial and institutional support for the necessary research (a topic beyond the scope of this paper), but we already know a great deal. For example, providing good facilities increases cycling, and cycling benefits health. ${ }^{9}$ Consumption of healthy food depends on its price and availability ${ }^{1}$ and these could be influenced by policies, for example, on taxes and subsidies. Food promotion can adversely influence children's food choices, ${ }^{17}$ and this could also be addressed by government policy. And there are many more such examples.

In this respect Wanless fails to grasp the nettle: the implementation model is seen as a health service function, primarily at the local level. This is not a purely UK problem; while the existence of the British NHS encourages the view that improving health should be a health service function - that 'the NHS should become a "health" service not just a "sickness" service' - the conflation of health with health care is by no means confined to the UK. For example, the draft EU constitution states, "A high level of human health protection shall be ensured in the definition and implementation of all Union policies and activities", but this is subsumed under the heading "Health care". ${ }^{18}$ (A similar provision in earlier treaties has not been translated into practice.)

For a report with a primary focus on effectiveness and cost effectiveness it is odd that this view is accepted uncritically (especially as the now highly decentralised NHS structure is not well suited to this role). What is the evidence for this being the best approach? Some evidence against the effectiveness of locally provided services is quoted in the report (page137), but ignored when drawing conclusions: in a prospective, controlled trial, TV antismoking advertising proved effective, whereas locally organised antismoking campaigning was not. ${ }^{19}$

More consistent attention to implementing healthy public policy, and amassing the evidence for it, are urgently required. The Wanless Report has opened the door, but refuses to go through it.

\section{$\checkmark$ Epidemiol Community Health}

2004; 58:966-968.

doi: $10.1136 /$ jech. 2004.023697

\section{Authors' affiliations}

M Joffe, J Mindell, Department of

Epidemiology and Public Health, Imperial

College London, London, UK

Correspondence to: Dr M Joffe, Department of Epidemiology and Public Health, Imperial College London, St Mary's Campus, Norfolk

Place, London W2 1PF, UK; m.joffe@imperial. ac.uk

Funding: none.

Conflicts of interest: none declared.

\section{REFERENCES}

1 Wanless D. Securing good health for the whole population. London: HM Treasury, 2004.

2 Wanless D. Securing our future health. London: HM Treasury, 2002.

3 Mckeown T. The role of medicine. Oxford: Basil Blackwell, 1979.

4 Szreter S. Rethinking McKeown: the relationship between public health and social change. Am J Public Health 2002;92:722-5.

5 Hansell A, Knorr-Held L, Best N, et al. COPD mortality trends, 1950-1999 in England and Wales-did the 1956 Clean Air Act make a detectable difference? [Abstract]. Epidemiology 2003;14:S55

6 Clancy L, Goodman P, Sinclair H, et al. Effect of air-pollution control on death rates in Dublin, Ireland: an intervention study. Lancet 2002;360:1210-14

7 Delves HT, Diaper SJ, Oppert S, et al. Blood lead concentrations in United Kingdom have fallen substantially since 1984. BM 1996;313:883-4

8 Pocock SJ, Smith M, Baghurst P. Environmental lead and children's intelligence: a systematic review of the epidemiological evidence. BMJ 1994:309: 1189-97.

9 British Medical Association. Road transport and health. London: British Medical Association, 1997.

10 Marmot MG. Tackling health inequalities since the Acheson Inquiry. J Epidemiol Community Health 2004;58:262-3.

11 Rose G. The strategy of preventive medicine. Oxford: Oxford University Press, 1992

12 Townsend J, Roderick P, Cooper J. Cigarette smoking by socioeconomic group, sex, and age: effects of price, income, and health publicity. $B M$ 1994;309:923-7.

13 Mindell J, Whynes DK. Cigarette consumption in the Netherlands 1970-1995: does tax policy encourage the use of hand-rolling tobacco? Eur J Public Health 2000;10:214-19.

14 Joossens L, Raw M. How can cigarette smuggling be reduced? BMJ 2000;321:947-50.

15 Bannock J, Baxter RE, Davis E. Penguin dictionary of economics. 6th ed. London: Penguin Books, 1998.

16 Buck D, Godfrey C, Raw M, et al. Tobacco and jobs. York: Centre for Health Economics, University of York, 1995.

17 Hastings G, Stead M, McDermott L, et al. Review of research on the effects of food promotion to children. Final report, prepared for the Food Standards Agency. Glasgow: Centre for Social Marketing, University of Strathclyde, 2003. http://www.food.gov.uk/multimedia/pdfs/ foodpromotiontochildren 1.pdf (accessed 5 Jul 2004).

18 The European Convention. Draft treaty establishing a constitution for Europe. Brussels: The European Convention, 2003. http:// european-convention.eu.int/docs/Treaty/ cv00850.en03.pdf (accessed 5 Jul 2004)

19 McVey D, Stapleton J. Can anti-smoking television advertising affect smoking behaviour? Controlled trial of the Health Education Authority for England's anti-smoking TV campaign. Tobacco Control 2000;9:273-82.

\section{Assessing psychosocial/quality of life outcomes in screening: how do we do it better?}

\section{Kirsten J McCaffery, Alexandra L Barratt}

\section{High quality research on the psychosocial outcomes of screening programmes is urgently needed.}

A ssessing non-medical outcomes of screening presents constant challenges. Marteau and colleagues ${ }^{1}$ offer some insight into the complexities of assessing non-medical outcomes in their study of abdominal aortic aneur- ysm (AAA) screening. The paper reports that self assessed health (SAH) was lower among men who were found to have an aortic aneurysm than men who did not, yet baseline measurement indicated that much of this difference pre-dated screening. Poorer SAH seemed to predict having an aortic aneurysm. The authors suggest that the findings have implications for the methods used to assess psychological impact of screening tests and warn us not to erroneously conclude that poorer outcomes are necessarily a product of screening, if baseline differences are not assessed.

Marteau et al' $\mathrm{s}^{1}$ findings are extremely interesting and raise important issues for the assessment of psychosocial or quality of life (QOL) outcomes in the screening context. Adequate assessment of psychosocial as well as medical outcomes, is crucially important, especially given the potential of screening to detect inconsequential disease ${ }^{2-4}$ but presents

Abbreviations: $\mathrm{SAH}$, self assessed health; $\mathrm{QOL}$, quality of life 


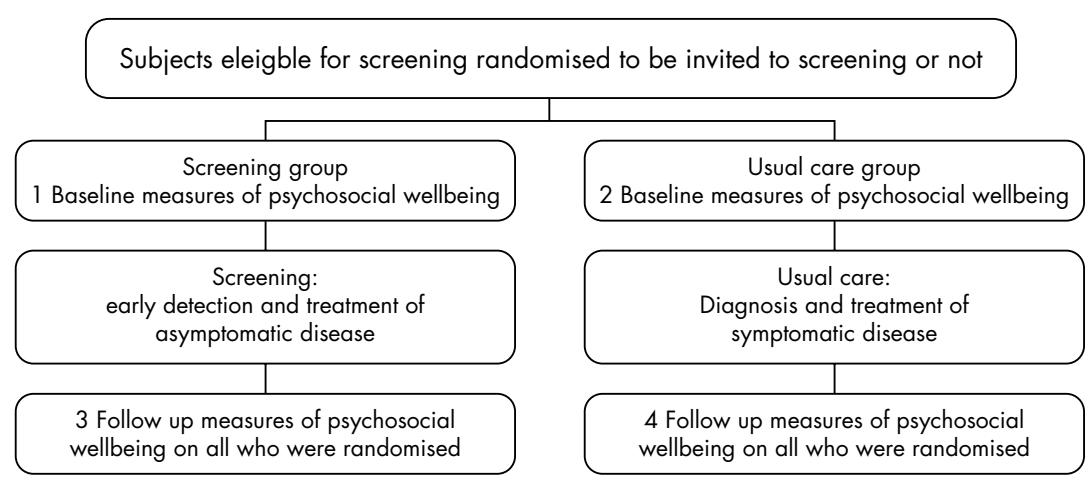

Figure 1 Design of randomised trials for valid estimation of the psychosocial impact of screening.

many challenges. These have received comparatively little attention. We have identified three main methodological concerns: (1) the need for a control group (preferably created by randomisation); (2) the need for baseline and follow up measurements; (3) the need for reliable measurement tools with high criterion and content validity.

The first concern, obtaining an adequate control group, perhaps presents the most difficulty. If our goal is to assess the impact of screening we need to measure the combined impact of the screening procedure, follow up tests, and treatments. The best way to achieve this is to randomise people to be screened or not screened and to measure the psychosocial impact on everyone at multiple times (see fig 1 ), in a way that is analogous to the assessment of the medical outcomes of screening. ${ }^{2}$ This would mean that, as well as establishing, for example, the mortality rate from breast cancer (in a trial of mammography screening) in all those randomised to screening and all those randomised to usual care, the investigators would need to measure average QOL effects in these groups as well. Investigators will thus have to ensure appropriate measures are taken from those randomised to screening who (1) do not respond to the screening invitation; (2) test negative (including those who are truly negative and those who later are discovered to be false negatives); ( 3 ) test positive (again both true and false positives), or from random samples of people in each of these groups. Comparable measures will also be needed in the usual care group, including in those who do and do not seek screening through alternative systems. Some of the test positive group will in fact have inconsequential disease, but as this is not identifiable on an individual level, the only way to estimate the psychosocial impact of this is by comparison of the screened group as a whole with the usual care control group. Clearly this will add to the complexity and challenges of data col- lection for randomised trials of screening, but comparatively small sample sizes will be needed for psychosocial outcomes (compared with medical outcomes). Furthermore, efficiencies may be achievable by carefully designed sampling strategies. In summary, it should be feasible to validly answer questions about the real psychosocial impact of screening in this way.

Alternatively in some circumstances other designs may be feasible. For example, people could be randomised to receive or not receive their results and subsequent tests and treatments, with follow up of psychosocial outcomes. Such designs have commonly been used in the past to evaluate screening for risk factors such as high cholesterol and high blood pressure in terms of medical outcomes. ${ }^{2}$

The second concern is the importance of taking baseline and follow up measures in both screened and unscreened groups. All psychosocial/QOL studies obviously take measures after screening (point 3, see fig 1), and many, as in Marteau's study, ${ }^{1}$ take them before and after testing (points 1 and 3). However, we have been unable to find studies that have taken and reported measures at points 1, 2, 3, and 4 (see fig 1) or more. In particular, measures are rarely taken and/or reported among appropriate controls, at points 2 and 4 . For example, a study by Wardle et $a l^{5}$ assessed anxiety among adults randomised to receive information about sigmoidoscopy screening and asked if they would be interested to attend, or not, but follow up measures were not reported in either arm.

Thirdly, it is imperative to select instruments that adequately capture psychosocial outcomes/QOL. What exactly constitutes psychosocial outcomes or QOL is often loosely defined. QOL itself has been described by many researchers as an atheoretical construct $^{6-10}$ and there is little clear consensus about what should or should not be used to adequately assess it, particu- larly in the context of screening. Most psychological and QOL measures are designed for use in patient populations and as such they are designed to capture relatively large decrements in QOL/wellbeing. Screening may lead to comparatively small decreases in psychological wellbeing/QOL but the decrement may occur across very large numbers of people so may still be important. Use of general psychological/QOL measures may not be sensitive enough to capture all outcomes. Some screening specific measures have been developed to combat this problem, for example, perceived consequences questionnaire, ${ }^{11}$ cervical screening questionnaire, ${ }^{12}$ and the PEAPS Q. ${ }^{13}$ It has been argued recently that such measures should be used to assess screening outcomes rather than other widely used generic measures. ${ }^{14}$ However, the need for quantitative measures that can be equated to and calibrated against other adverse health outcomes and events is crucial if we are to truly gain a measure of how screening affects the wellbeing of individual's and populations. Once the psychosocial/QOL impact of a screening test is adequately captured it may then be weighed against the test's medical outcomes to comprehensively evaluate its worth as a screening tool.

Marteau's study ${ }^{1}$ also raises interesting questions about what represents QOL/psychosocial outcomes. Although consensus on QOL/psychosocial measurement is limited, most evaluations include some component of emotional and social functioning with a measure of perceived health or physical functioning sometimes also included. Marteau ${ }^{1}$ reports only perceived health (SAH). The finding that $\mathrm{SAH}$ is poorer after screening in the group with screen detected aortic aneurysms is not at all surprising. The purpose of screening is to identify people at increased risk of disease and inform them of their status. As such, the finding that a person rates their health as poorer after an abnormal screening result is an inevitable consequence of screening, and perhaps may be viewed as an indication that a person has understood their test result, rather than a measure of psychosocial wellbeing.

This brings us to Marteau's $\mathrm{s}^{1}$ finding that $\mathrm{SAH}$ was poorer before screening in men who subsequently had aneurysms found, predicting AAA even after adjustment for known risk factors. This is a puzzling finding-why should a person's perception of their health status predict whether they have an asymptomatic condition? It could be that the results are explained by the failure to measure smoking at baseline and adjust for it appropriately. However, 
given the arguments presented by the authors and the very small change in the odds ratios for SAH after adjustment of other known AAA risk factors (age, family history, blood pressure, and social deprivation), it is quite possible that even if smoking was included, $\mathrm{SAH}$ would still remain an independent predictor of AAA. Alternatively the finding might be related to an increased likelihood of other symptomatic cardiovascular conditions that affect SAH among the screen positive group.

If, however, the association is not the result of such factors, then it presents us with an astonishing finding, that asymptomatic AAA in some way makes people feel recognisably less well. This seems hard to believe especially as most of the aneurysms identified by screening in the study were comparatively small. Nevertheless it raises the question of whether SAH might be a predictor of disease in other screening programmes, such as cancer or heart disease. Could it be possible that people who are subsequently found to have colorectal cancer or bowel polyps have poorer SAH before screening, or that women who have cervical intraepithelial neoplasia have poorer perceived health? These speculations seem unlikely but not impossible and we are unaware of any evidence to support or refute them, other than the substantial body of evidence that SAH is a strong predictor of mortality, especially among men. ${ }^{15}$ Thus the association between SAH and clinical outcomes of other screening tests would seem to warrant investigation. The finding raises the possibility that screening pro- grammes of the future might incorporate tests of SAH. This is of course a highly speculative suggestion and one that would need much, much more investigation.

In conclusion Marteau et al's ${ }^{1}$ study highlights the urgent need for high quality research on the psychosocial outcomes of screening programmes. Just as with medical outcomes, the strongest designs will be randomised trials with before and after screening measurements. We believe it is feasible and important to include validated psychosocial measures within future randomised trials of screening.

\section{ACKNOWLEDGEMENTS}

We would like to thank Professor Les Irwig for comments on an earlier version of this paper.

$J$ Epidemiol Community Health 2004;58:968-970.

doi: $10.1136 /$ jech. 2004.025114

....................

\section{Authors' affiliations}

K J McCaffery, A L Barratt, Screening and Test Evaluation Program, University of Sydney Australia, School of Public Health, University of Sydney, Sydney, Australia

Correspondence to: Dr A L Barratt, Screening and Test Evaluation Program, University of Sydney Australia, School of Public Health A27 University of Sydney, Sydney, NSW 2006 ,

Australia; alexb@health.usyd.edu.au

Funding: none.

Conflicts of interest: none declared.

\section{REFERENCES}

1 Marteau TM, Kim LG, Upton J, et al. Poorer self assessed health in a prospective study of men with screen detected abdominal aortic aneurysm: a predictor or a consequence of screening outcomes? J Epidemiol Community Health 2004:58: 1042-6.

2 Barratt A, Irwig L, Glasziou P, et al. Users' guides to the medical literature. XVII. How to use guidelines and recommendations about screening. JAMA 1999;281:2029-34.

3 Black W, Welch $\mathrm{H}$. Advances in diagnostic imaging and over-estimations of disease prevalence and the benefits of therapy. N Engl J Med 1993;328:1237-43

4 Zahl PH, Strand BH, Maehlen J. Incidence of breast cancer in Norway and Sweden during introduction of nationwide screening: prospective cohort study. BMJ 2004;328:921-4.

5 Wardle FJ, Taylor T, Sutton S, et al. Does publicity about cancer screening raise fear of cancer? Randomised trial of the psychological effect of information about cancer screening. BMJ 1999;319:1037-8

6 Hornquist JO. The concept of quality of life. Scand J Soc Med 1982:10:57-61.

7 Gill TM, Feinstein AR. A critical appraisal of quality of life measurements. JAMA 1994;272:619-26.

8 Bowling A. Measuring health: a review of quality of life measurement scales. 2nd ed. Philadelphia: Open University Press, 1997.

9 Hunt SM. The problem of quality of life. Qual Life Res 1997;6:205-12.

10 Smith AE. Quality of life: a review. Education and Ageing 2000;15:419-35.

11 Cockburn J, De Luise T, Hurley S, et al. Development and validation of the PCQ: a questionnaire to measure the psychological consequences of screening mammography. Soc Sci Med 1992;34: 1129-34.

12 Wardle J, Pernet A, Stephens D. Psychological consequences of positive results in cervical cancer screening. Psychol Health 1995; 10:185-94.

13 Bennett A, Irwig L, Oldenburg B, et al. PEAPS-Q: $A$ questionnaire to measure the psychosocial effects of having an abnormal pap smear. J Clin Epidemiol 1995;48: 1235-43.

14 Brodersen J, Thorsen H, Cockburn J. The adequacy of measurement of short and long-term consequences of false positive screening mammography. J Med Screen 2004:11:39-44.

15 Idler EL, Benyamini Y. Self-rated health and mortality: a review of twenty-seven community studies. J Health Soc Behar 1997; 38:21-37. 